\title{
Colombia: ¿dónde encontrar la necesitada paz? ¿En las elecciones?
}

Rafael Vergara

$\mathrm{N}$ o es extraño al hablar de Colombia referirse a la paz, sin embargo, según los análisis de los grandes inversionistas extranjeros, en ese país sudamericano está históricamente instalada la "democracia más estable de América Latina”. El desangre diario no se ve, las múltiples guerras cuyo escenario de batalla es la sociedad misma, tampoco son tenidas en cuenta.

Las evidencias en vidas humanas: 51 muertes violentas diarias en promedio, secuestros a granel, combates en los campos, bombas en las ciudades, extradiciones de nacionales y muerte de opositores, juecesy candidatos presidenciales, son hechos cotidianos que asombran y hieren el inconsciente colectivo que-sin tregua-acumula al siguiente día un nuevo crimen igual o de mayor intensidad.

Hay guerra pero el crecimiento económico no se afecta, las inversiones crecen, el parlamento sigue funcionando, las obras públicas y privadas no se detienen, el pais en nombre del latinoamericanismo sigue entregando - a costa de la sangre e intranquilidad nacional- la soberanía jurídica y económica; mientras, barcos norteamericanos, a los ojos de América Latina y en abierta violación de tratados internacionales, detienen e inspeccionan un carguero colombiano que navegaba en aguas caribeñas.

El país vive alimentando múltiples violencias, es la tendencia dominante. 


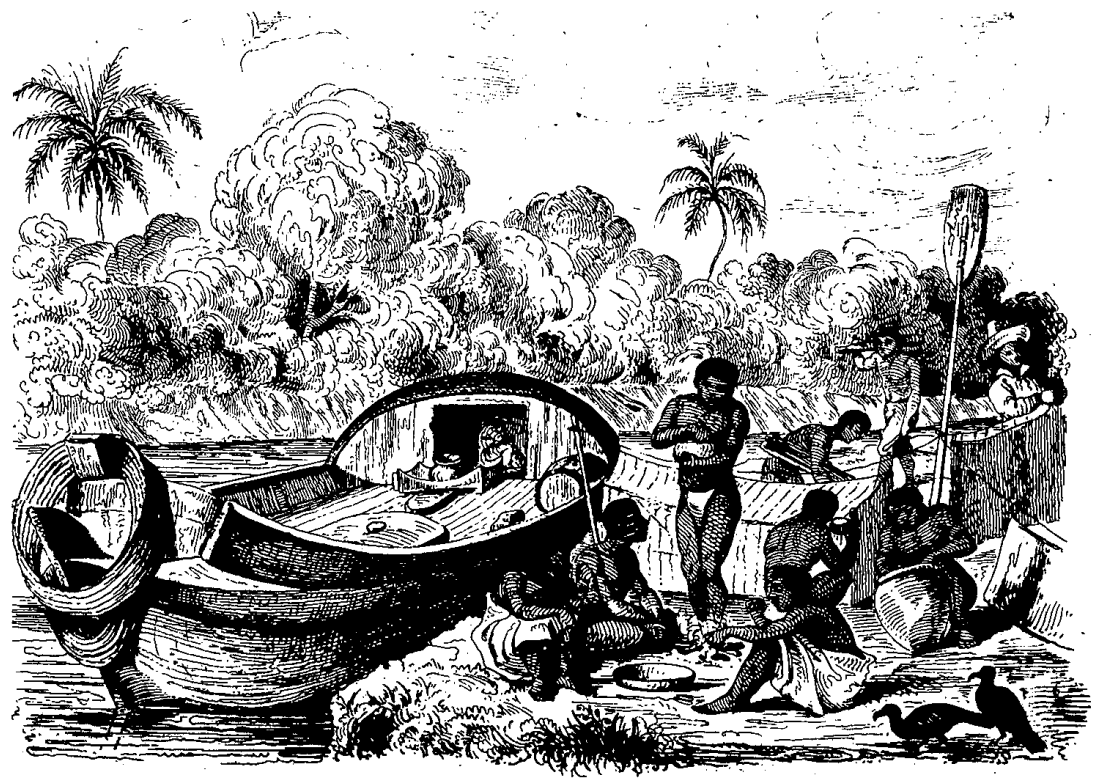

No hay ética ni códigos de conducta en esta tragedia colombiana, la guerra se alimenta de la guerra que toda legislación contrainsurgente requiere para prolongar el conflicto o la barbarie, para legalizarlo, en los términos doctrinales de la remodelación democrática planteada por el presidente George Bush.

Colombia siempre ha vivido en guerra, su historia es la de las guerras civiles, hay una costumbre de violencia. Liberales y conservadores, durante todo el siglo XIX y hasta el pacto del Frente Nacional en 1957 , recurrieron a las armas para dirimir sus conflictos programáticos. El pacto, excluyente de alternación constitucional de la presidencia y reparto paritario de todos los cargos de la administración pública, abrió paso al surgimiento de la insurgencia armada de orientación marxista, pero también a la institucionalización de la llamada "democracia repre- sentativa", con todas sus características de intolerancia y violencia.

El carácter de un régimen político de naturaleza antidemocrática -no toda la sociedad podía ser liberal-conservadorainstitucionalizó el uso casi permanente del estado de excepción como complemento necesario de los mecanismos de dominación política. El estado de sitio eterno.

La pazse pactó entre las cúpulas de los partidos tradicionales y sus bases consensuales activas y pasivas, no así con la inmensa mayoría de la población marginada de los beneficios sociales.

De las guerrillas liberales de los años 1948-53, las que no fueron aniquiladas con el asesinato de sus líderes o caudillos amnistiados, fueron exterminadas en acciones de limpieza contra el bandolerismo, actividad en que algunas habían degenerado. 
Si bien la despolitización planteada como meta del modelo de alternancia daba algunos frutos pacificadores, el salto a la consolidación de una hegemonía liberal-conservadora-militar estimulaba el rechazo y las expresiones armadas de diferente matiz ideológico. El país había cambiado, el poder comenzaba a fragmentarse y el nuevo espectro político y social desafiaba las nuevas instituciones.

Colombia se urbanizó gracias a la violencia en el campo, pero la tenencia de la tierra no se democratizó, todo lo contrario. Las enormes masas migrantes se instalaron a la fuerza en la periferia de las ciudades. La ausencia de empleo, servicios públicos y vivienda, condiciones mínimas de sobrevivencia, se fueron constituyendo en el caldo de cultivo de la protesta cívica y también una criminalidad social que alcanza límites de asombro.

Sólo en 1983 las estadísticas oficiales reportan 213034 casos de delitos contra el patrimonio económico y 66165 contra la integridad personal, 150470 corresponden a hurtos y 18953 a homicidios; hoy, esa escandalosa cifra se incrementa vertiginosamente: 51 muertos diarios en promedio.

Pese a la alarma de los organismos internacionales de defensa de derechos humanos, Colombia es además la "democracia más antigua de América Latina" y las elecciones han sido fundamentales para consolidar este útil espejismo. Hay "guerra sucia contra todos los demócratas. Pero hay guerra también contra los marginales: prostitutas, pequeños delincuentes, homosexuales, mendigos y contra los gamines o niños de la calle (...). Para esta guerra existe un nombre cínico: la limpieza. ${ }^{1}$ Quien comenta este

'Adolfo Pérez Esquivel, "Colombia otra guerra", en ElMundo. hecho macabro es Adolfo Pérez Esquivel, premio Nobel de la paz.

Aunque existe un marco de formalidad democrática, un estado de derecho-cercenado, por cierto-, el derecho humanitario sólo existe como letra muerta en esta guerra de aniquilamiento constante.

El asesinato y la impunidad se han erigido como el método principal de la dominación política y la conservación del poder, "cerca de 1000 asesinatos políticos en 1986, 1651 en 1987, 3011 en 1988 y cerca de 1500 , entre enero y junio de $1989^{\prime \prime},{ }^{2}$ confirman las características del modelo político. El silenciamiento es histórico y la crisis, consustancial con el sistema. Nació así la república . El asesinato del mariscal Antonio José Sucre en 1830 es el más dramático del siglo XIX; nunca socialmente se supo quién lo ordenó; iniciando el siglo XX, uno entre los más destacados liberales, el general Rafael Uribe, jefe en la guerra de los mil días -así se le conoce-, fue también asesinado y tampoco se supo de los autores intelectuales; Jorge Eliecer Gaitán fue asesinado denunciando, como "tribuno del pueblo", ${ }^{3}$ la lacra de la impunidad. En ese 1948 aniquilar la idea política y matar lentamente se funden como estrategia conceptual de guerra, se trata de extenderle la agonía al ser humano; 20000 muertos es el saldo de la masacre; el genocidio y la muerte selectiva extendida por Colombia ocupan un lugar desde entonces. El hoy de la violencia viene del asesinato impune de Gaitán. En ese instante de la historia, liberales y conservadores pierden el monopolio de la ideologia, de la guerra.

${ }^{2}$ Ibid.

${ }^{3}$ Título otorgado por las masas populares al caudillo liberal. Gaitán, abogado penalista, senador, ministro, jefe del Partido Liberal. 
De las guerrillas liberales nacen las comunistas... y de las comunistas todas las formaciones guerrilleras agrupadas en la Coordinadora Guerrillera Simón Bolivar: Fuerzas Armadas Revolucionarias de Colombia, Ejército de Liberación Nacional, Ejército Popular de Liberación, Movimiento 19 de Abril, Partido Revolucionario de los Trabajadores, Comando Indígena Quintín Lame.

Todas surgen como respuesta obvia al modelo excluyente y autoritario del Frente Nacional.

Como lo expresara recientemente Gonzalo Sánchez, uno de los llamados violentólogos:

Los asesinatos y las masacres, ya no tienen como límite una frontera que defina el "más acá" o el "más allá" [...] nos estamos acercando de manera suicida a la guerra total [...] es una guerra de todos contra todos, en una sociedad con un altísimo porcentaje de su población armada o protegida por las armas. Es una guerra no sólo punitiva sino también preventiva contra quien se supone puede llegar a ser subversivo, traidor o simplemente contendiente en el escenario más amplio de la política o el más discreto de las relaciones interpersonales. ${ }^{4}$

Para Gonzalo Sánchez no sólo es una guerra contra el Estado o del Estado contra la sociedad civil, es "una guerra de la sociedad entera consigo misma. Es el suicidio colectivo que al agudizarse no proyecta una crisis insurreccional sino una anarquía generalizada". Pero pese a este duro panorama todos los índices crecen en Colombia, incluida la abstención electoral.

\footnotetext{
${ }^{4}$ Gonzalo Sánchez, "Opinión de un 'violentólogo' de la nueva generación", Semana, 3 de mayo de 1988.
}

Aunque parezca increible, en medio del caos el crecimiento de ingreso por habitante en dólares de 1986 ha tenido el siguiente comportamiento:

$$
\begin{array}{ll}
1960=747 & 1980=1277 \\
1970=926 & 1986=1390^{5}
\end{array}
$$

Esto no significa que hayan disminuido los índices de marginalidad pues la concentración económica sigueacumulándose en la cúspide de la pirámide de la distribución de los beneficios: en 1982 "el ingreso per cápita del 10\% más rico es 73 veces superior al del $10 \%$ más pobre". Colombia es de los pocos países de América Latina que crecieron en los años de la crisis. La razón es clara: aumento de las exportaciones legales y sobre todo de las ilegales, y esto es evidente si tenemos en cuenta la correlación directa de la caída del crecimiento del pIB y la campaña antidrogas. emprendida por las administraciones de Reagan y Bush.

Hoy se estima que las inversiones productivas del narcotráfico, recicladas a la actividad económica, representan un $30 \%$ del PIB que en la actualidad es de 34000 millones de dólares. $^{?}$

Aunque no es el tema central de esta ponencia, vale la pena aclarar que el hoy de la sociedad colombiana está indisolublemente ligado a este hecho. Lo electoral, losocial,lo militar, lo económico, la

sJorge Méndez Monevar, La distribución de ingresos en Colombia, Universidad Nacional de Colombia, Bogotá, 1985, mimeo.

${ }^{6}$ Informe especial "La nueva Colombia", Semana, 27 de septiembre de 1988.

${ }^{7} \mathrm{Al}$ respecto existen diferencias de criterio. Para algunos interesados en subvalorar y subvaluar la participación en el pibésta es de 3\%. Otros como Salomón Kalmanovich hablan de $9 \%$ del PIB y $30 \%$ de la riqueza nacional. Nuestrocálculo parte de considerar un ingreso anual promedio de 3000 millones de dólares reciclados legal e ilegalmente a la economía nacional. 
Gráfica 1

TASA DE CRECIMIENTO ANUAL DEL PIB EN COLOMBIA

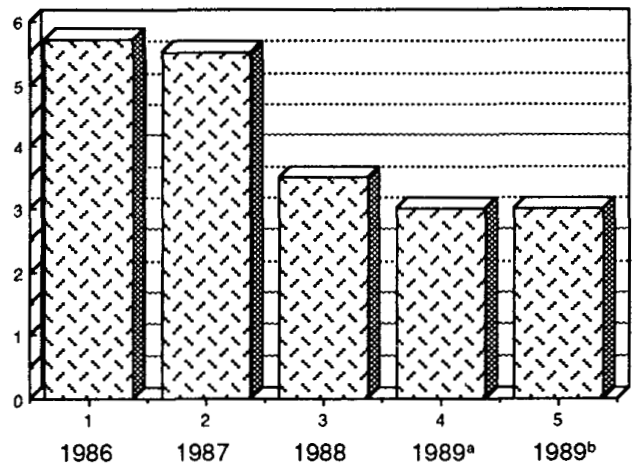

Estimado

b Proyectado

Fuente: Banco de la República, DANE

"Informe especial "Sombras de recesión”, Semana, 24 de octubre de 1989.

política de empleo, el diseño de la política internacional, la violencia, la distribución de ingresos, todo tiene que ver con el narcotráfico y la evolución del conflicto planteado en torno a la represión o negociación con este factor de poder en un país fracturado y sometido a grandes presiones por parte de la política intervencionista del gobierno de EUA. En el referenteeconómico, el narcotráfico-que entre otras cosas emplea de manera directa e indirecta a 1500000 colombianos-puede afectarla proyección de $3.5 \%$ del crecimiento económico planteado por las autoridades monetarias del país. Así lo ve el FMI quien, en su informe para 1990, expresa que el sector externo "sentirá plenamenteel impacto dela caída de los precios del café y de la lucha contra la droga sobre la cuenta corriente, que arrojará un déficit de $2.3 \%$ del PIB". 8

\footnotetext{
${ }^{8}$ Economía y negocios "Con la bendiciôn del
} Fondo", Semana, 13 de febrero de 1990.
ELECCIONES, VIOLENCIA Y NEGOCIACIÓN

Con esta descripción parcial del panorama político nacional es posible entrar a nuestro tema central: las elecciones y la paz.

Qué se elige, quiénes eligen, por qué, cómo y para qué se desarrolla una contienda electoral son preguntas necesarias si tenemos en cuenta las especifidades y complejidades deun país dondela muerte tiene permiso y la guerra campea cotidianamente, aunque la abstracción intente suplantar con ficción la realidad lacerante hasta aquí descrita.

Para comenzar baste decir que en los últimos 58 años $95 \%$ de las elecciones colombianas se han realizado bajo estado de sitio. Este ignorado hecho marca diferencia con el resto de los países de América Latina y caracteriza las campañas y resultados obtenidos por la clase política colombiana.

La abstención en los últimos 25 años 
supera $65 \%$ del potencial de votantes ${ }^{9} \mathrm{y}$ las elecciones del 11 de marzo de 1990 no fueron una excepción.

La abstención calificada de "inusitada" por reconocidos analistas políticos, "mostró la incapacidad del bipartidismo de recuperar su legitimidad", ${ }^{10}$ pero paradójicamente, frente a los resultados exiguos obtenidos por las nuevas fuerzas, significó "el afianzamiento del control territorial por parte de los partidos tradicionales, con un claro predominio de la histórica mayoría liberal y la cada vez más inocultable crisis del partido conservador". ${ }^{11}$ Pese a los altísimos incrementos de costos de cada elección y la utilización de técnicas publicitarias sofisticadas y modernizantes, lo que parece quedar claro es que la abstención es funcional para el sistema político tradicional. Las discusiones entre el gobiemo y el Movimiento 19 de Abril en relación a la necesidad de implantar el voto obligatorio, despejan las dudas al respecto.

Mientras el M-19 incluía la obligatoriedad como punto básico de la negociación hacia su desmovilización militar, los negociadores gubernamentales con múltiples argumentos aplazaron y en sintesis, negaron someter a aprobación del constituyente primario, esta medida. Y es claro: si la abstención ilegitima el sistema democrático, la afectación resulta menor cuando el ejercicio del voto es un deber, es decir, un acto voluntario del ciudadano.

En un país de institucionalidad híbrida cívico-militar la obligatoriedad del voto, con las sanciones obvias al abstencionista, dejaría aún más al descubierto

${ }^{9}$ iA Luchar!' núm. 93, 28 de febrero de 1990.

${ }^{10}$ Fabio A. Sandoval Pérez, "¿La oportunidad de la izquierda?", Cien Días, cINEP, vol. 3, núm.9, marzo de 1990 , p. 8.

${ }^{11}$ Francisco José Reyes, "El día de los elegidos", Cien Días, cinep, vol. 3, núm. 9, marzo de 1990, p. 4. los conflictos y el repudio al sistema político.

Lo que está en el fondo de la cuestión es la existencia de un país tradicional, clientelista, manejado en este aspecto de la política por gamonales de lealtades patriarcales a los jefes locales y nacionales de los partidos liberal y conservador.

En Colombia las "sorpresas" electorales en cargos de importancia nacionalo departamental son poco probables, gracias al férreo control del llamado electorado cautivo.

El $88 \%$ de los municipios registra la misma filiación política mayoritaria desde hace 50 años y las últimas elecciones asi lo confirmaron.

Con excepción de la elección en 1970 del general Gustavo Rojas Pinilla como presidente de la república-elección, entre otras, burlada por el Frente Nacional-, salvo el recambio de filiación de un liberal a un conservador o viceversa, es poco probable que el "voto de opinión", el voto por lo nuevo, derrote al "voto de maquinaria". No hay que olvidar que el tradicionalismo caracteriza los regímenes oligárquicos y que los intentos de modernización o racionalización en el seno del propio sistema chocan con los viejos intereses que han sido el soporte de la dominación política.

De hecho, las elecciones del 11 de marzo de 1990 son una clara expresión de lo expuesto, y de allí su importancia innegable.

Estas eleccionesfueron realizadas con dos fines institucionales y uno extrainstitucional: se trató, en primera instancia, de elegir representantes para corporaciones públicas: senadores, representantes, diputados departamentales, consejeros municipales e intendenciales y alcaldes populares. ${ }^{12}$

\footnotetext{
${ }^{12}$ Principal autoridad ejecutiva de carácter municipal.
} 


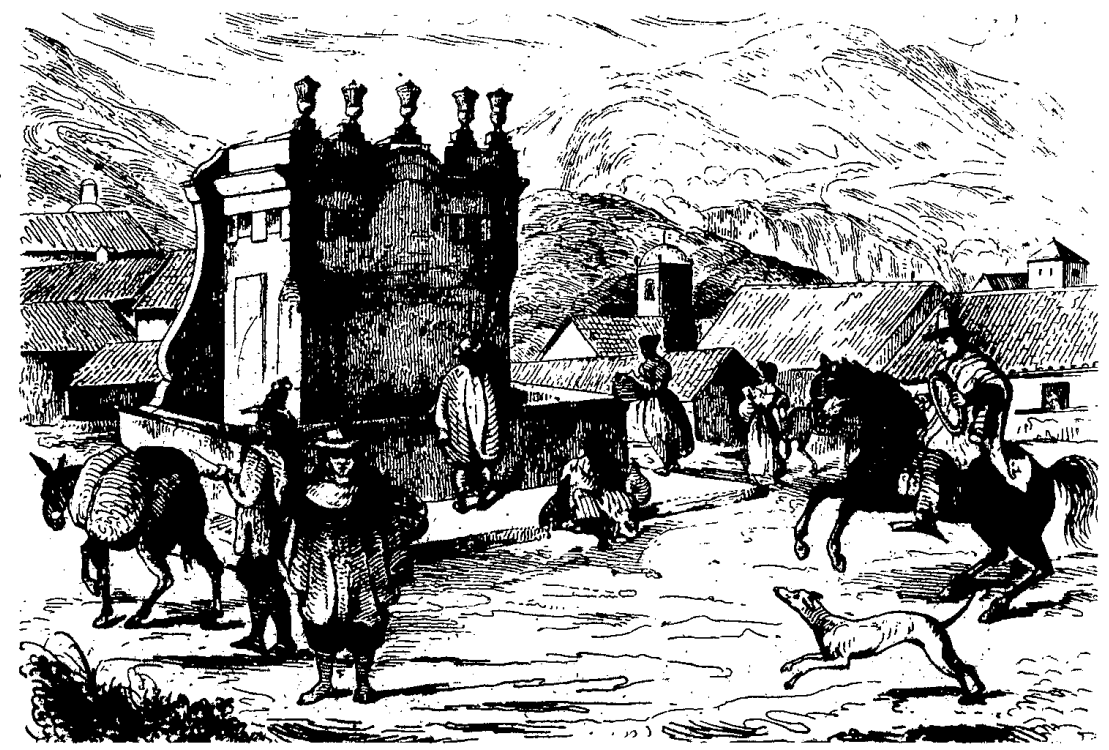

Valga anotar que la elección popular de alcaldes responde a la llamada "apertura política betancurista" 13 que, mediante la reforma constitucional de 1986, amplió el espacio de participación ciudadana y reajustólasinstituciones del poder buscando con ello una mayor legitimación del sistema.

Como segundo fin institucional, el 11 de marzo el partido liberal -en un hecho sin antecedentes- sometió a "consulta popular" la elección de su candidato a la presidencia de la república, garantizando así su unidad en los comicios a realizarse en mayo de este año.

De entre siete candidatos tradicionalistas y modernizantes fue elegido César Gaviria, quien reemplazó al candidato Luis Carlos Galán, antiguo representante del llamado nuevo liberalismo, disiden-

\footnotetext{
${ }^{13}$ Belisario Betancur, presidente conservador (1982-86).
}

cia táctica asimilada por el oficialismo, y quien fuera asesinado en agosto de 1989 por el cártel de Medellín en pleno desarrollo de su campaña electoral.

Lo que resulta claro es la imposibilidad de ilusionarse con el candidato liberal elegido por la vía de la llamada consulta popular, pues como afirman los analistas: "Gaviria es la encarnación del compromiso de lo nuevo con la tradición clientelista"14 y en buena medida representa-pese a la diferencia generacionalla continuidad con el gobierno del presidente Virgilio Barco. Como hombre del establecimiento ocupó en dicha administración el Ministerio de Hacienda y posteriormente de Gobierno, en momentos en que el país vivió la expansión de los grupos paramilitares (140 reconocidos oficialmente) y la imposición de la

\footnotetext{
${ }^{14}$ Camilo Castellanos, "Ningún prodigio", Cien Dias, Cinep, vol. 3, núm. 9, marzo de 19\%0, p. 4.
} 
más autoritaria legislación contrainsurgente: el Estatuto Antiterrorista.

La votación extrainstitucional correspondió a la llamada "séptima papeleta", que consultó a los electores sobre la conveniencia o inconveniencia de convocar una Asamblea Nacional Constituyente, con el fin de abrir camino a una reforma de la antiquísima Constitución de 1886 y lograr con ella un espacio para el ejercicio de la democracia participativa.

Ysi bien el voto fue mayoritariamente favorable a la convocatoria, el mandato contenido en este importante acto del electorado, imponeuna obligación moral a quien salga electo presidente.

Si bien la constituyente puede ser la fórmula para desbloquear la histórica dificultad política impuesta por el tradicionalismo para reformar la constitución, nada garantiza que la composición de la misma deje de ser bipartidista. Este será el reto para la sociedad civil y las organizaciones de izquierda, agobiadas por la violencia y las maquinarias políticas.

\section{LOSCOMPORTAMIENTOS ELECTORALES}

Pilar Gaitán, politóloga de la Universidad Nacional de Colombia, en un excelente estudio sobre la elección popular del alcalde, ${ }^{15}$ expresa conceptos que son fundamentales para comprenderla situación electoral del país y la gran importancia de esta institución.

En sintesis afirma que esta reforma tardía pretendió adecuar la conflictiva geografía política del país mediante la institucionalización de los movimientos y la protesta cívica, una de las principales

${ }^{15}$ Pilar Gaitán, "Primera elección popular de alcaldes", Análisis Político, núm. 4, mayo-agosto de 1988. formas de lucha en pos de la obtención o mejoramiento de los servicios públicos. "Descentralizar los conflictos, cooptary desarticular el movimiento social de las municipalidades, revitalizar la acción de los partidos tradicionales y lograr que las comunidades locales se apropiaran de este instrumento", fue el autodesafio que se planteó el sistema político.

Si bien existen logros al respecto, el militarismo, telón de fondo del reformismo institucional, y $s u$ "guerra sucia", se convirtieron en el principal obstáculo: 140 alcaldes, concejales, candidatos a alcaldias y diputados departamentales fueron asesinados entre 1986 y 1988. De 1988 a la fecha, la política de exterminio del opositor o "enemigo interno" se ha incrementado, presentándose el hecho de las matanzas en aquellos lugares donde la oposición, representada por la Unión Patriótica, ha resultado mayoría.

Es claro que las "investigaciones" no han conducido a desactivar esta doble política del Estado que con una mano abre los espacios y con la otra dispara y los sepulta.

Es la expresión de la intolerancia del sistema político, reflejo de esa dualidad peligrosa y funcional del estado contrainsungente... "de derecbo".

En estas condiciones, la canalización de la oposición armada mediante este instrumento no ha resultado plenamente útil a los intereses de la reforma.

Asil las cosas, el pretendido cambio de la geografía política no se ha dado y, por el contrario, la mayoría de las alcaldías han quedado en manos de liberales y conservadores. La eficacia del clientelismo y las maquinarias electorales, a más del militarismo, han impedido el surgimiento del multipartidismo, expresión política vital si lo que se pretende es la integración de los intereses colectivos 
a la institucionalidad y el control legal de los conflictos sociales.

Losasesinatos, la persecución política a la oposición y el monopolio del electorado por parte del bipartidismo, han determinado que las nuevas fuerzas tengan un carácter marginal, lo que en sí estimula el abstencionismo y la incapacidad del sistema para lograr los consensos sociales necesarios para estimular la paz social requerida en una verdadera democracia.

Sin embargo existe una excepción, nueva, creativa y de una importancia crucial para el futuro electoral del país.

Si bien $88 \%$ de los municipios tienen desde hace 50 años la misma filiación mayoritaria liberal o conservadora, las elecciones de 1988 vieron irrumpir el fenómeno de los "otros inscritos", que muy por encima de $0.8 \%$ de la votación de la Unión Patriótica (16 alcaldías), obtuvo 101 alcaldías de las 1009 en disputa.

\section{COMPORTAMIENTOELECTORAL} ELECCIÓN POPULAR DE ALCALDES

$\begin{array}{lrr}\text { Liberales } & 446 & 44.2 \% \\ \text { Nuevo } & & \\ \text { liberalismo } & 8 & 0.8 \% \\ \text { Conservadores } & 413 & 40.9 \% \\ \text { Unión } & & \\ \text { Patriótica } & 16 & 1.6 \% \\ \text { Coaliciones } & 25 & 2.5 \% \\ \text { Otros } & 101 & 10.0 \%\end{array}$

Fuente: Registraduría Nacional del Estado Civil.

Como claramente lo expresa la politóloga Pilar Gaitán: lo innovador de los comicios es que los otros "eluden la referencia meramente partidista para movilizar a la ciudadanía y utilizan formas inéditas y múltiples de agrupamiento". Se trata de alianzas múltiples y multipar- tidistas o no partidistas integradas por disidencias de los partidos tradicionales, Unión Patriótica, Frente Popular y otras organizaciones políticas y territoriales, movimientos cívicos y comunitarios que integran organizaciones indígenas, campesinas y de pobladores.

Sus candidatos permiten la confluencia de diversos sectores sociales y políticos y por lo tanto -a diferencia de los candidatos del bipartidismo- poseen amplio consenso.

Estamos frente al surgimiento de una nueva democracia, irepresentará este fenómeno la ruptura del tradicional bipartidismo y el surgimiento de la democracia participativa?

Es claro que este fenómeno sui generis de la "democracia colombiana", fuera de todo esquema, es el resultado de la lucha democrática emprendida desde la oposición política y la base social misma.

Aunque en él participan liberales y conservadores independientes, ello no invalida el enorme potencial en la transformación tan necesaria de los comportamientos electorales, más aún si lo que subyace es la urgencia de crear espacios decontienda política civilizada y el logro de legitimidad en la representatividad y participación popular.

\section{EL MOVIMIENTO 19 DE ABRIL Y LAS ELECCIONES}

Las elecciones de marzo de 1990 contaron con la participación de una nueva fuerza en la contienda electoral. Pese a que se frustró el referendo pactado entre el gobierno colombiano y el M-19 mediante el cual el Congreso debía aprobar la realización de una consulta directa al constituyente primario, dicha organización, con un mínimo de tiempo de campaña, participó en los comicios. 


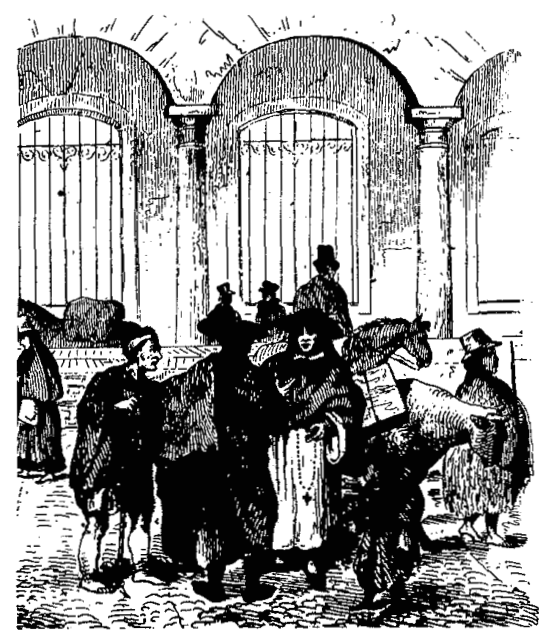

Sin circunscripción nacional electoral de $p a z^{16}$ la competitividad resultaba mínima; sin embargo, Carlos Pizarro, comandante de esa organización, obtuvo 80000 en la votación para la alcaldía de Bogotá, configurándose como la tercera fuerza. El excelente resultado electoral, si se tiene en cuenta lo expuesto, abrió paso a su candidatura presidencial que, sin lugar a dudas, representó en ese momento una opción de paz en el país violento que hemos venido analizando.

Según encuestas realizadas, el cálculo de la votación para Pizarro oscilaba entre 700000 y 1000000 de votos. En sus propias palabras:

Mi candidatura no sería legítima, ni útil, resultaría indeseable si no tuviera la capacidad de impulsar tres grandes propósitos:

1. Servir de catalizador para la unidad del pueblo y dentro de ésta edificar una

\footnotetext{
${ }^{16}$ La circunscripción electoral nacional de paz tenía como finalidad permitir al M-19 un acceso diferencial, por una vez, a los cargos de representación.
}

fuerza capaz de conducirla a la victoria.

2. De proyectar esa nueva fuerza y sus líderes auténticos a la dimensión de constituyentes, en esta hora suprema de Colombia en la cual es posible suscribir, como decíamos, un auténtico tratado de paz entre todos los colombianos.

3. Abrir, a través de su victoria, un puente transitable para que todos los sectores alzados en armas se aproximen a una solución política definitiva que les abra reales espacios en el futuro de la sociedad colombiana.

Porque nuestra candidatura debe ser la clave para alcanzar la paz real, la paz duradera, integral y estable que retire el arma de las manos de todos aquellos factores de violencia que por distintas razones, legitimados o no o empujados por diversas circunstancias hacen hoy uso de la violencia para dirimir sus conflictos. ${ }^{17}$

El 25 de abril del presente año, Colombia, América Latina y el mundo despertaron con una detonadora noticia: Carlos Pizarro fue asesinado dentro de un avión en vuelo. Tresbalazos de una miningram de fabricación israelí, disparados por un suicida, ponían fin a la vida de otro candidato presidencial, el tercero en menos de seis meses.

El inconsciente colectivo sufrió un nuevo y duroimpacto. La violencia segaba la vida de quien fue capaz de llevar a su organización a dejar las armas para ejemplificar sobre la necesidad de la paz.

¿Quién lo asesinó? Nunca, como siempre, se sabrá.

Las elecciones fueron empañadas.

Mientras, una información conduce a la reflexión: "La inversión extranjera en 1989 superó en $149 \%$ a la de $1988 .{ }^{" 18}$

${ }^{17}$ Carlos Pizarro, "Discurso del día de lanzamiento de su candidatura", 19 de abril de 1990 , mimeo.

18 "La inversión externa en Colombia en 1989", Unomásuno, 14 de enero de 1990. 